\title{
Effects of forming velocity on micro deep drawing performance with different blank thickness
}

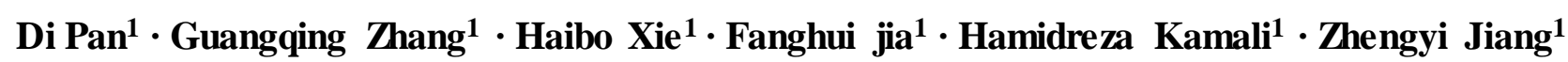

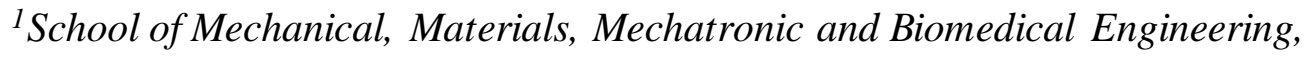

University of Wollongong

Wollongong, NSW 2522

Australia 


\section{Abstract}

Micro deep drawing is a promising manufacturing method to produce the hollow, thin walled, cup or box like products at micro scale. Forming velocity can affect the products' quality significantly due to the size effect, and this effect can be various with different thickness material. In this study, 30, 40, and $50 \mu \mathrm{m}$ thickness stainless steels were annealed at $950{ }^{\circ} \mathrm{C}$ for $2 \mathrm{~min}$ under protection of argon gas ambient respectively. These different thickness steels were utilized in the micro deep drawing with different forming velocities. The experimental results show that, the profile accuracy and surface quality of the micro product are affected by changing the forming velocity with different thickness blanks. The micro cup has a less indentation area at the bottom and becomes rounder and more symmetrical with a thicker blank. Besides, the wrinkling phenomenon turns distinct with a thinner blank, and the earing becomes more significantly when increasing the drawing velocity or decreasing the blank thickness. When the drawing velocity or blank thickness increases, the surface of the micro cup becomes smooth and even. The experimental results are in good agreement with the simulation results, which confirms the developed finite element simulation model is applicable.

Keywords: Micro deep drawing $\cdot$ Size effect $\cdot$ Forming velocity $\cdot$ Material thickness $\cdot$ SUS301 


\section{Introduction}

Manufacturing at micro scale becomes important in the modern society due to the increasing demand of the micro products in auto, medical, electrical communication, and aerospace industries. Besides, the pollution, volume and cost of the products can be reduced significantly by minimising the forming scale $[1,2]$. The microforming technologies can be divided into two types, namely, microsystem technologies (MST) and micro-engineering technologies (MET) [3]. Generally, MST contains micro wire EDM, lithographic technologies, and micromachining, which are widely used to produce micro components with high accuracy. However, these methods have high operation cost and can only be sued in a narrow range of workpiece materials. By contrast, MET are mainly related to mechanical machining, and these technologies transfer the conventional manufacturing to the micro scale [3, 4]. The MET can be utilized to manufacture high-precision mechanical components with the smooth surface. Furthermore, based on the type of machined materials, microforming can be classified as silicon-based or non-silicon-based manufacturing technologies $[5,6]$. Above all, plastic microforming is a preferred micro manufacturing technology due to the high productivity, low product cost, and less pollution. This microforming technology can be transferred from the conventional manufacturing process, which has well developed principle and theory at macro scale [7-10]. However, the principle and theory of conventional plastic forming cannot be directly transferred to the micro scale due to the size effect, which can cause the difference on the stress flow, formability, fracture behaviour, and friction of the material between the macro scale and micro scale [11-14]. To produce thin walled, hollow, box or cup like products at micro scale, micro deep drawing (MDD) is a fundamental process of the micro plastic forming, and more complex micro products can be produced based on this technology [2,15]. Therefore, it is essential to find a theory to be used in producing high-quality micro parts and explain the frictional behaviour during the MDD [16-19]. There are several researches have been conducted to improve the profile accuracy, surface quality, and forming ability of the micro products in MDD [16, 20-23]. Generally, friction and strain during the process are crucial elements to determine these characters of the micro cups [24]. Coating the diamond-like carbon (DLC) film on the tool surface is efficient to reduce the friction and improve the forming ratio in the MDD, and this method is not suitable for mass production [25]. Therefore, the nanoparticle lubricant can be used to improve the micro product's quality, namely, the lubricant can form an adhesive film to uniform the stress during the process [26-31]. Besides, the thickness of the drawing material and the drawing velocity can influence the friction and strain significantly, then affect the quality of the micro products [32-34].

This study presents an experimental study in forming different thickness austenite SUS301 micro cups with different forming velocities. The vertical view, side view and the surface quality of the 
micro products are observed by the 3-D laser microscope, and the efficiency of the MDD is expected to be enhanced via altering the drawing velocity. Besides, the products' quality can also be affected by the thickness of the material. Even though, the volume can be diminished distinctly with a thinner blank, the product quality could be defected more significantly. The finite element (FE) model of MDD process is established to simulate this study, the drawing velocity and experimental material thickness are altered to explore the relationship between these factors and micro product's quality, then compare the results between the experiment and simulation to confirm the developed FE model for MDD process [35-37].

\section{Experimental}

\subsection{Experimental material}

The SUS301 sheet was used in this study, and the material was manufactured by cold rolling to obtain 30,40 , and $50 \mu \mathrm{m}$ thickness metal pieces respectively, which are satisfied the specification of die sets in MDD. The chemical composition of SUS301 is listed in Table 1, and this material is annealed in $950{ }^{\circ} \mathrm{C}$ for $2 \mathrm{~min}$ in the KTL tube furnace under the protection of argon ambient, which is efficie nt to prevent the material oxidation.

Table 1 Chemical compositions of SUS301

\begin{tabular}{ccccccccc}
\hline $\mathbf{C}$ & $\mathbf{S i}$ & $\mathbf{C r}$ & $\mathbf{M n}$ & $\mathbf{N i}$ & $\mathbf{N}$ & $\mathbf{P}$ & $\mathbf{S}$ & $\mathbf{F e}$ \\
\hline 0.15 & 0.75 & $16.00-18.00$ & 2.00 & $6.00-8.00$ & 0.10 & 0.045 & 0.030 & Balance \\
\hline
\end{tabular}

\subsection{Micro deep drawing}

In order to manufacture the box-like product at micro scale, the MDD is carried out on a Desk-top press machine, which is shown in Fig. 1 (a). This press machine can provide up to $25 \mathrm{KN}$ press force and the drawing velocity can be controlled by the control box as shown in Fig. 1 (b). The drawing process occurred in the die set, which contains the upper and lower dies, besides, the geometrical parameters are shown in Table 2. During the MDD, the material was placed to the gap between the upper and lower dies, then the force was applied on the top of the upper die. As shown in Fig. 2, there are the force sensor, upper blank holder and punch in the upper die; the lower die contains spring, lower blank holder, and die cavity. This figure shows the principle of the MDD, and this process contains blanking stage and drawing stage. In the blanking stage, the lower die holder acts as the blanker punch, which moves upward and cut a round blank form the experimental material, then this blank is fixed by the upper and lower blank holders, and the punch moves downward to punch the round blank into die cavity. After that, a micro cup is manufactured. 
Table 2 Parameter of press machine DT-3AW and process

\begin{tabular}{|l|l|l|l|l|}
\hline $\begin{array}{l}\text { Punch diameter } \\
(\mathrm{mm})\end{array}$ & $\begin{array}{l}\text { Die diameter } \\
(\mathrm{mm})\end{array}$ & $\begin{array}{l}\text { Radius of punch } \\
\text { fillet }(\mathrm{mm})\end{array}$ & $\begin{array}{l}\text { Radius of die } \\
\text { fillet }(\mathrm{mm})\end{array}$ & $\begin{array}{l}\text { Initial blank } \\
\text { diameter }(\mathrm{mm})\end{array}$ \\
\hline 0.8 & 0.975 & 0.3 & 0.3 & 1.6 \\
\hline
\end{tabular}

(a)

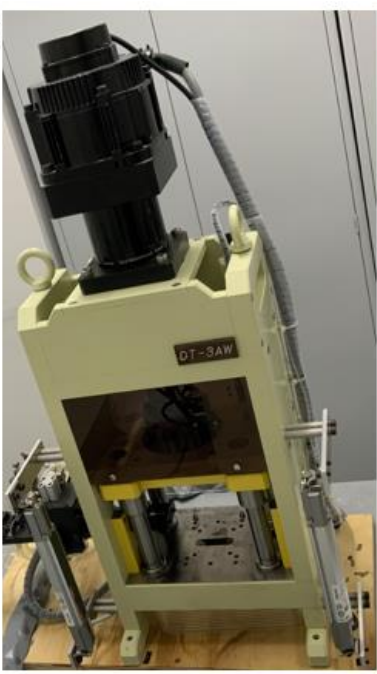

(b)

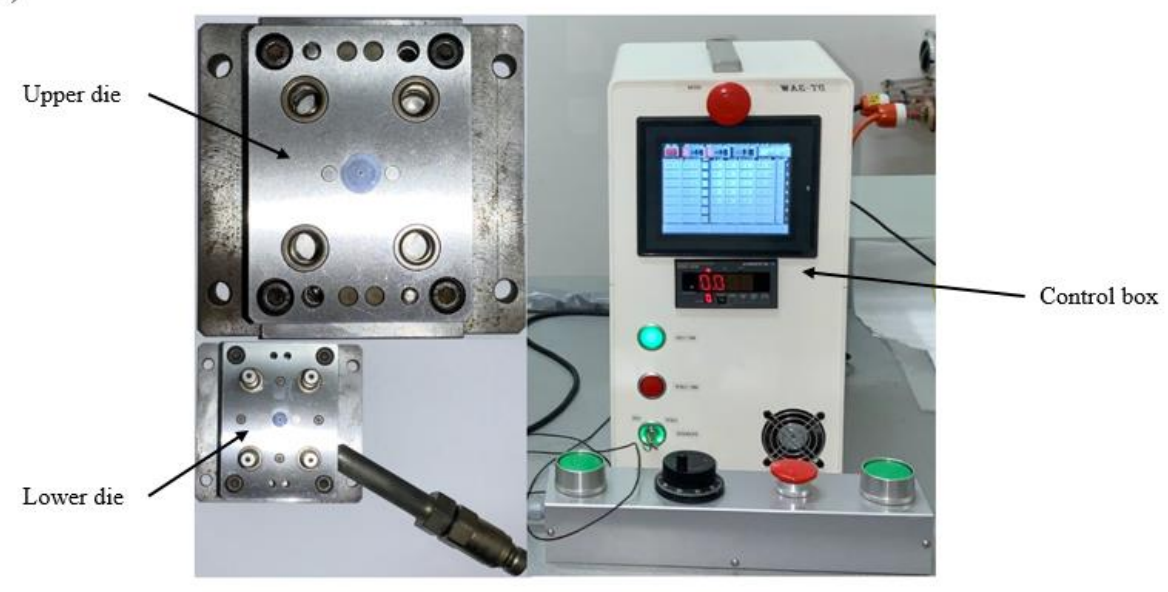

Fig. 1. MDD apparatus. (a) Press machine DT-3AW; (b) MDD die set and control box
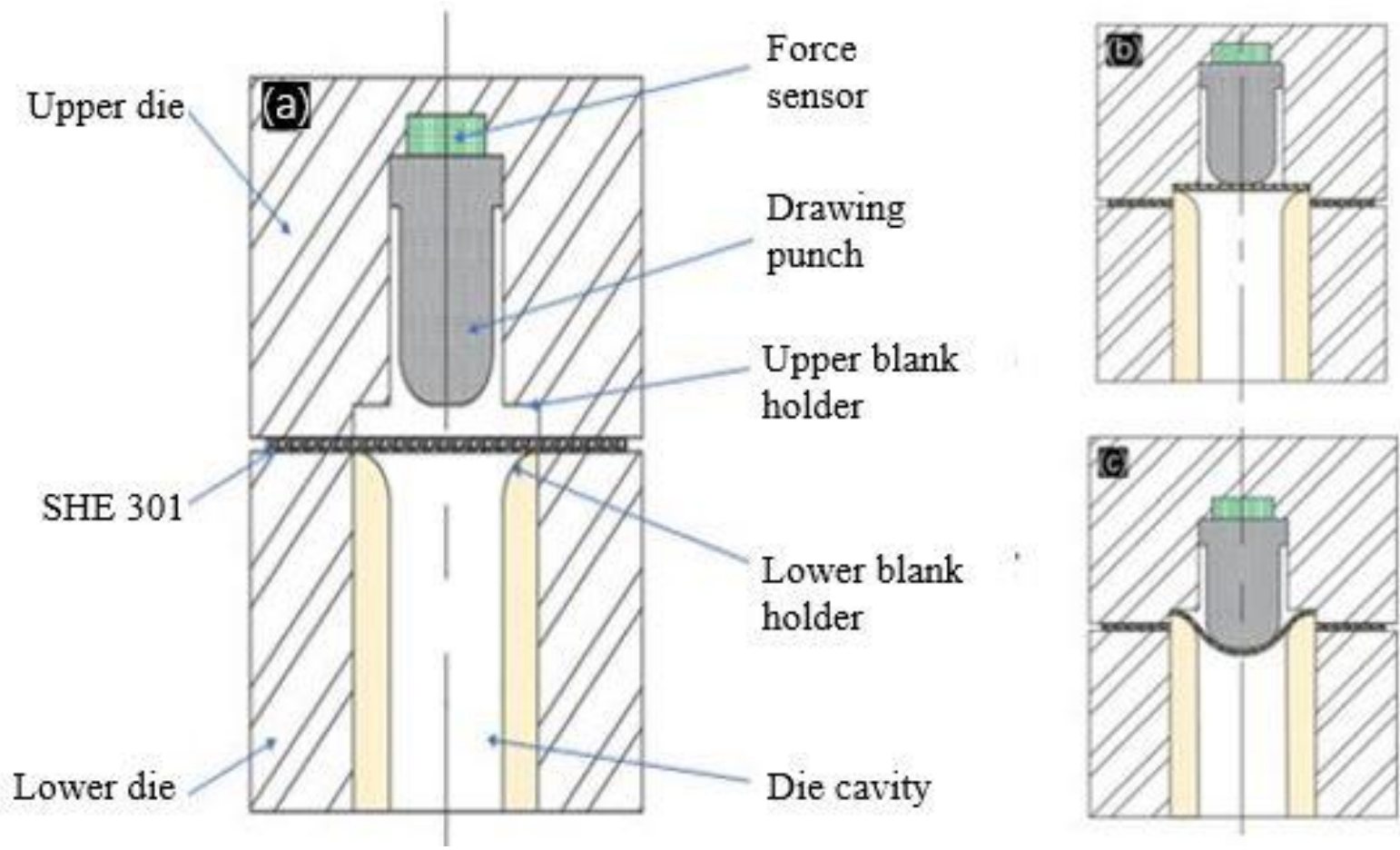

Fig. 2. Schematic of MDD processes: (a). Initial stage of MDD, (b) Blanking stage of MDD, (c) Forming stage of MDD 


\subsection{FE simulation}

To explore the effect of drawing velocity on the different thickness sample, FE modelling is an efficient method to determine this effect. In this study, the explicit dynamic analysis model was established as shown in Fig. 3, and 1/4 symmetrical model was set to simplify the simulation. Furthermore, the blank holders and punch were set as rigid analytical bodies, and sheets were builded as deformed shell model with $0.03,0.04$, and $0.05 \mathrm{~mm}$ respectively. As the relevant process parameters, the lower blank holder and die cavity are immobile, and the punch moves along the vertical direction with $0.1,0.2$, and $0.3 \mathrm{~mm} / \mathrm{s}$ velocity respectively. Besides, $20 \mathrm{MPa}$ was applied on the upper blank holder before the blank leaved the blank holder, and the other tool parameter was set as same as Table 2 .

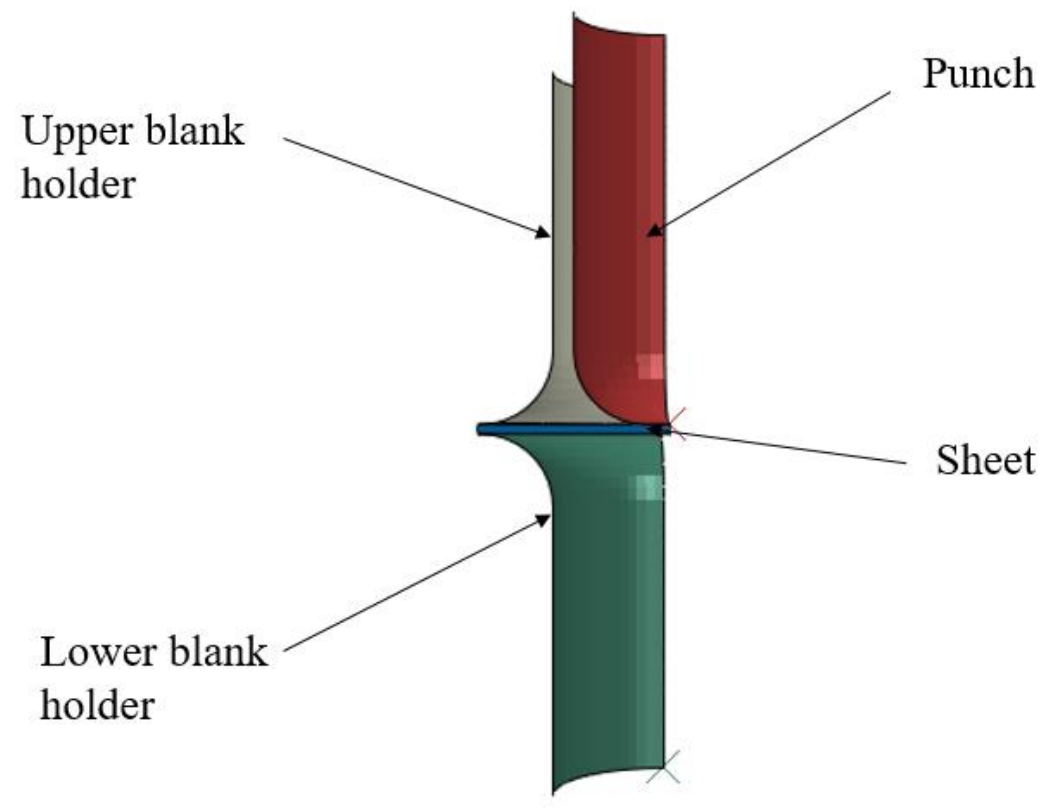

Fig. 3. FE model for analysis in numerical simulation

\section{Results and discussion}

The influences of forming velocities on the micro part's quality were distinct at micro scale, since the quantity of formed grain is obvious lower compared with the macro scale, which means the effect of the forming rate on the single grain becomes more significant compared with macro forming. Besides, the volume of forming material can be changed significantly due to the variation of the blank thickness at micro scale, and the ratio of thickness reduction increases with a decrease of the forming scale.

\subsection{Effect of blanking velocity on blank asperity with different thickness}

The different forming velocities of the sample can alter the strain rate during the forming process, and this variation can affect the sample's forming ability with various thickness. Fig. 4 shows the 
profile and side view of the blank under different blanking velocities with different thickness $(0.03$, 0.04 , and $0.05 \mathrm{~mm}$ ). The edge profile and side view of the blank edge were captured by the laser scan microscope, and the sheet tends to bend into the die cavity during the blanking process. From Fig. 4 (a), the different colours on the blank edge show the bending area, and the blank edge is not smooth and even. It can be seen that $0.04 \mathrm{~mm}$ blank with $0.1 \mathrm{~mm} / \mathrm{s}$ blanking velocity has the best edge quality comparing with other blanking velocity and thickness. Under this condition, the blank has the least bending area and jag phenomenon. Overall, the blank edge generates more jag phenomenon due to a rise of the blanking velocity with different sample thickness. Besides, the effect of blanking velocity becomes more obvious with a decrease of blanking thickness. The inhomogeneity of the material is more obvious with the thinner blank, because the less grain located on the formed path. Although, the forming ability of the blank is more homogeneous with the thicker blank, the blanking time can also increase with a rise of the thickness, then the possibility of bending and producing jag increases with more blanking time. Therefore, the bending and jag area of the $0.05 \mathrm{~mm}$ is more obvious compared with that of $0.04 \mathrm{~mm}$ sample due to the increase of blanking time. Fig. 4 (b) shows the side view of the blank edge with different thickness under different blanking velocities. Generally, there is burr on the side edge and the blank thickness is not even in the different conditions, and the edge's side quality was changed significantly with different thickness blanks under $950{ }^{\circ} \mathrm{C}$ heat treatment. From this figure, it can be seen that there are more burr and defects with a rise of the thickness, and the effect of the blanking velocity on side quality increases with a rise of blank thickness. More burr and uneven area can be generated with a higher blanking velocity, the unevenness and burr points of the blank side can be caused by inhomogeneous grain deformation of the cut area, and the microstructures of different thickness blank are different due to the size effects. Namely, the ratios of surface grains are significant different with various blank thickness.
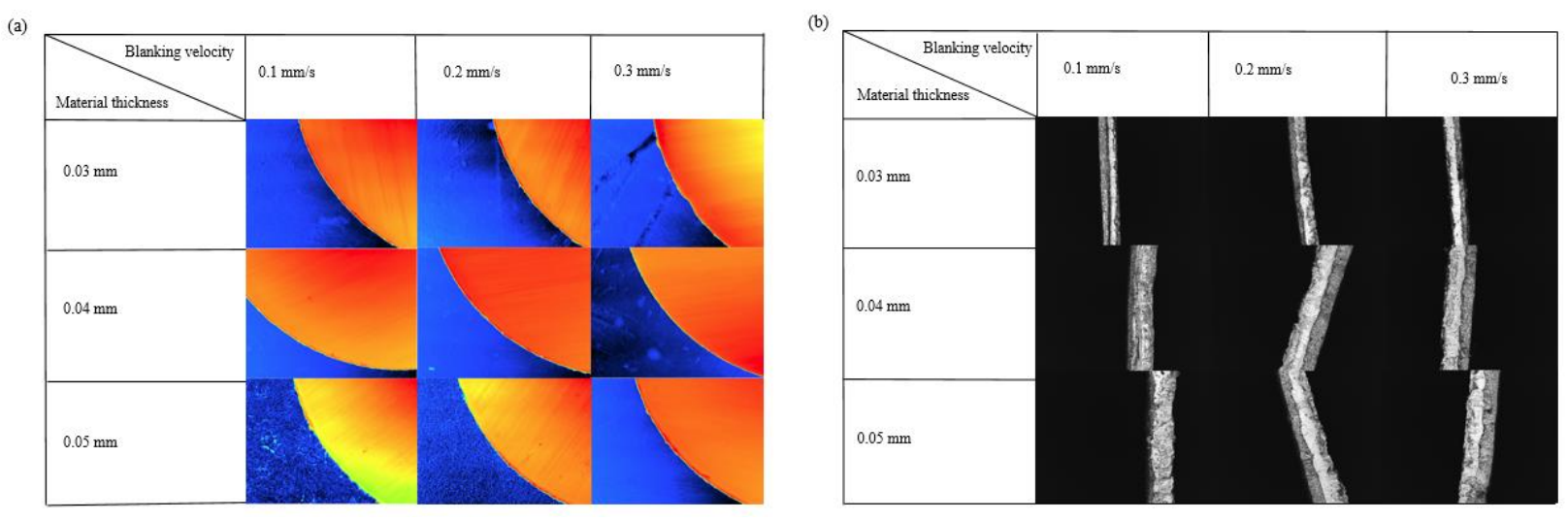

Fig. 4. 3D laser microscope image of different thickness blank with different blanking velocities: (a) edge profile, and (b) side view 


\subsection{Effect of velocity on deep drawing force}

Fig, 5 shows the comparison of drawing force to forming different thickness samples with various drawing velocities. The same trends of the drawing force to the displacement are the same for different thickness samples under various drawing velocities, and the drawing force increases with a rise of the thickness. As the punch moves downward during the drawing process, the dominated punch force is the resistance of bending, and the other force is small relatively, then the drawing force increases slowly. After the blank was bended slightly, the blank was close to the die fillet and the drawing force decreased slowly. Since the blank is slipped in the die cavity, the main drawing force transfers to the forming force at the flange, the friction between the blank and blank holder, and the friction between the blank and the die cavity. The drawing force increases rapidly as the punch moves downward, then this force reaches the peak point and remains a short period. As the deformation continues, the drawing force decreases to the end of the drawing process, and the drawing force is not zero at the end of the forming process, because the drawn cup needs to release the stored strain energy. From Fig. 5, the difference of drawing force with various drawing velocities is obvious when the thickness is $0.03 \mathrm{~mm}$, and the change of the drawing force is slightly between 0.1 and $0.2 \mathrm{~mm} / \mathrm{s}$ with $0.04 \mathrm{~mm}$ thickness blank before the drawing force reached the top point. When the blank thickness increased to $0.05 \mathrm{~mm}$, the drawing force is almost the same with 0.2 and $0.3 \mathrm{~mm} / \mathrm{s}$ drawing speeds before the drawing force reached the top point. In this stage, the drawing force decreases obviously with a rise of the drawing velocity. Since the extending area is increased with a lower drawing velocity before the blank slips into the cavity, and the friction could increase with a larger contact area.

After the drawing force reached the peak point, the drawing force decreases significantly to the end of the drawing process, and the reduction of drawing force is more significant with a decrease of the drawing velocity. Furthermore, the drawing force is larger with a higher drawing velocity during this stage. Meanwhile, the energy can be stored in the drawn cup, the springback can release the stored energy gradually. The last drawing force can describe this phenomenon because the drawn cup squeezed the punch at the end of the forming process, and then the last stroke drawing force is generated. Furthermore, more force could compress the punch, when the more stored strain energy needs to be released. The last drawing force of all conditions are recorded and plotted in Fig. 6. It can be seen that the last drawing force increases with a higher drawing velocity, which means the micro cup can store more strain energy due to a higher forming velocity. The high drawing velocity can cause a large strain rate on the blank during the MDD, and the more force squeeze the punch at the end of the drawing stage. Since the blank thickness can alter the microstructure and formability of the material, the influence of the forming velocity on the last drawing force is also different with the various thickness samples. Generally, the last drawing force increased with a rise of the blank 
thickness under the same drawing velocity, and the difference of the last drawing force between 0.03 and $0.04 \mathrm{~mm}$ thickness is more obvious than that of this difference between $0.04 \mathrm{~mm}$ and $0.05 \mathrm{~mm}$. The effect of drawing velocity on the last drawing force is not significant with $0.05 \mathrm{~mm}$ blank, and this effect becomes obvious with a decrease of the blank thickness. The grain becomes more crucial in the smaller volume during the forming process. Therefore, the difference of grain growth under the heat treatments becomes more significant with the thinner blank due to the less blank volume, and the effect of forming velocity on the single grain is more obvious due to the lower quantity of grains on the forming path.

(a)

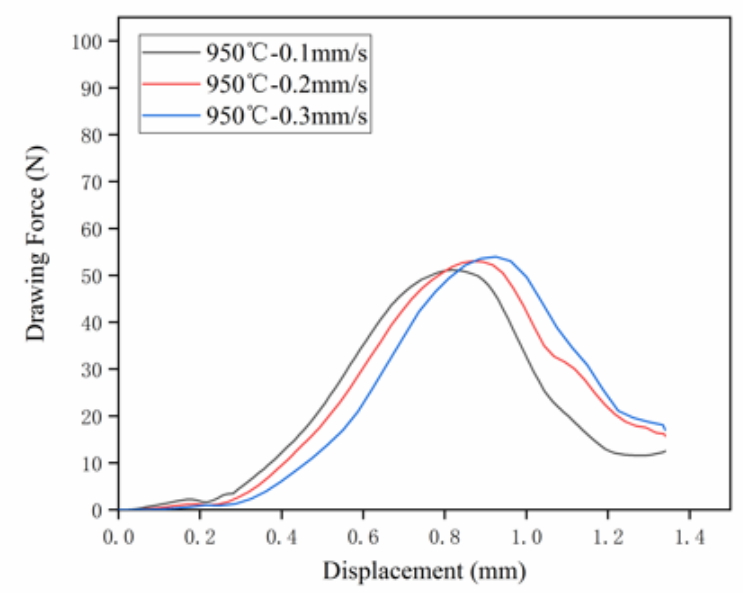

(c)

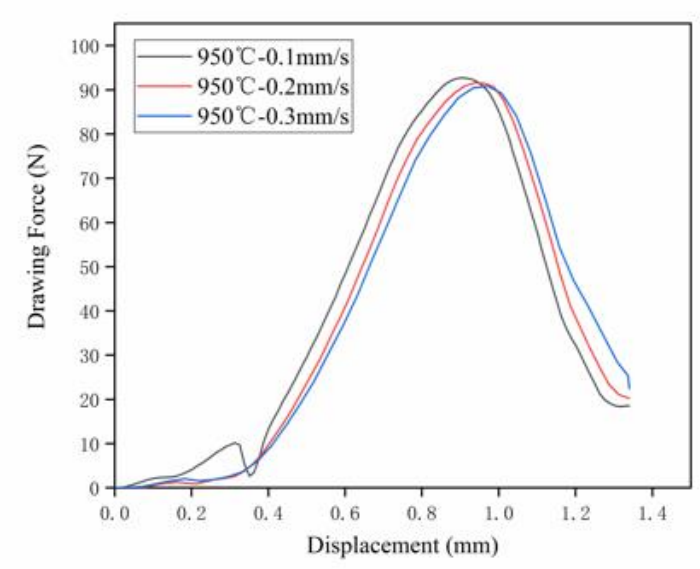

(b)

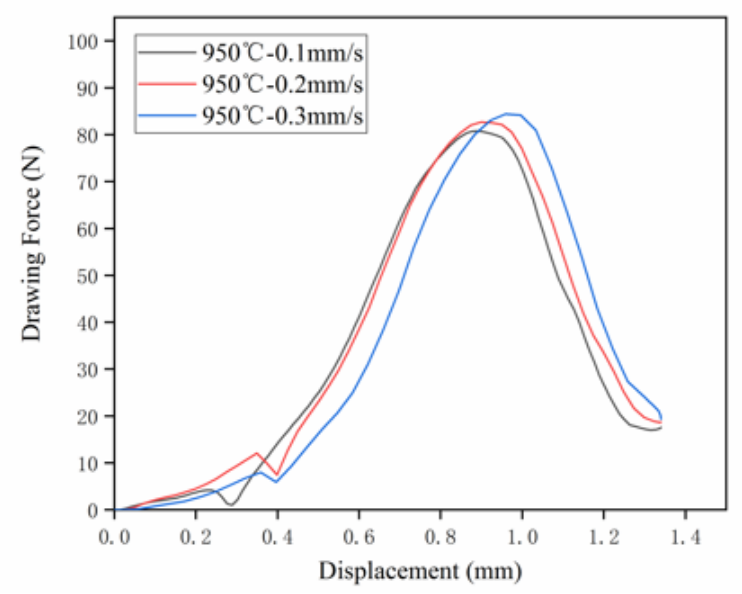

Fig. 5. Drawing force-displacement curve of different thickness under $950{ }^{\circ} \mathrm{C}$ heat treatment with different forming velocities: (a) $0.03 \mathrm{~mm}$, (b) $0.04 \mathrm{~mm}$, and (c) $0.05 \mathrm{~mm}$ 


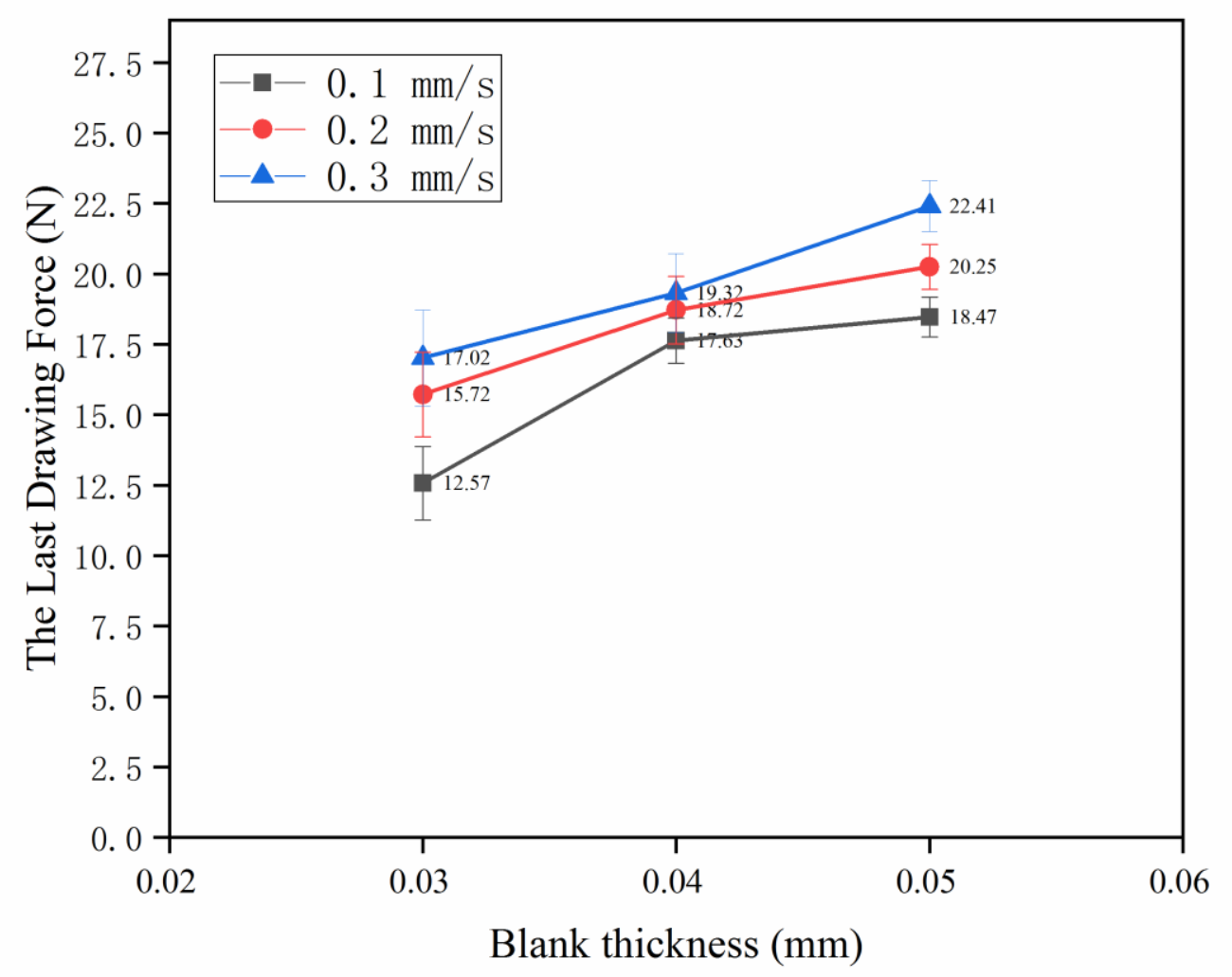

Fig. 6. The last drawing force of different thickness with different forming velocities

\subsection{Micro conical-cylindrical cups}

The profiles of the micro cups are almost same in the drawing die sets, and the experimental material thickness is a crucial element to affect the diameter and the height of the micro products. The profiles of different thickness micro cups are measured by the microscope, and the thickness of micro cup mouth can be measured by the inner and outer circle radius. Fig. 7 shows the micro cup mouth view with different thickness blanks, and the changes of the thickness are various. There is a slight increase on the micro cup mouth, when the blank thickness is $0.03 \mathrm{~mm}$, and the thickness of cup mouth increased to $0.033 \mathrm{~mm}$. However, the micro cup mouth became thinner when drawing the 0.04 or $0.05 \mathrm{~mm}$ blanks. The difference of micro cup mouth thickness variation among the 0.03, 0.04, and $0.05 \mathrm{~mm}$ blanks is caused by the distinction on the initial stage of the drawing process. Thus, the initial stage of drawing process contains the bending and compressing at the rim area of the blank and stretching on the wall area. When the blank thickness is $0.03 \mathrm{~mm}$, the blank slips into die cavity easily, then the compression time and force diminish, and the bending occurs more on the interior of the blank due to the insufficient blank holder force. Besides, the stretching on the cup wall becomes significant at the initial stage of drawing process, then the micro cup mouth becomes thicker. However, when the thickness is 0.04 or $0.05 \mathrm{~mm}$, the blank can be fixed firmly at the initial stage, 
and then the rim area can be formed and stretched long. Thus, the micro cup mouth becomes thinner than that of the original blank when a 0.04 or $0.05 \mathrm{~mm}$ blank is drawn. Fig. 8 shows the stress states of different thickness blanks at the initial stage of drawing in the simulation, and these states are close to the real experimental results. In the simulation result, the stress focus on the lower rim and wall area, when the blank thickness is $0.03 \mathrm{~mm}$. Besides, the focus area of stress moves to the rim of the blank with a rise of the thickness. Therefore, comparing with the blank original thickness, the micro cup mouth becomes thicker when drawing a $0.03 \mathrm{~mm}$ blank, and the cup mouth turns thinner when drawing a 0.04 or $0.05 \mathrm{~mm}$ blank. Furthermore, the profile accuracy of the micro cups could be improved due to the well formation on the blank rim. Fig. 9 shows the bottom view of the micro cups with different thickness, and the bottom of micro cup becomes rounder and more symmetrical with an increase of the blank thickness. When the thickness is $0.03 \mathrm{~mm}$, the bottom of micro cup has a significant indentation, and this indention area decreases significantly with a thicker micro cup.

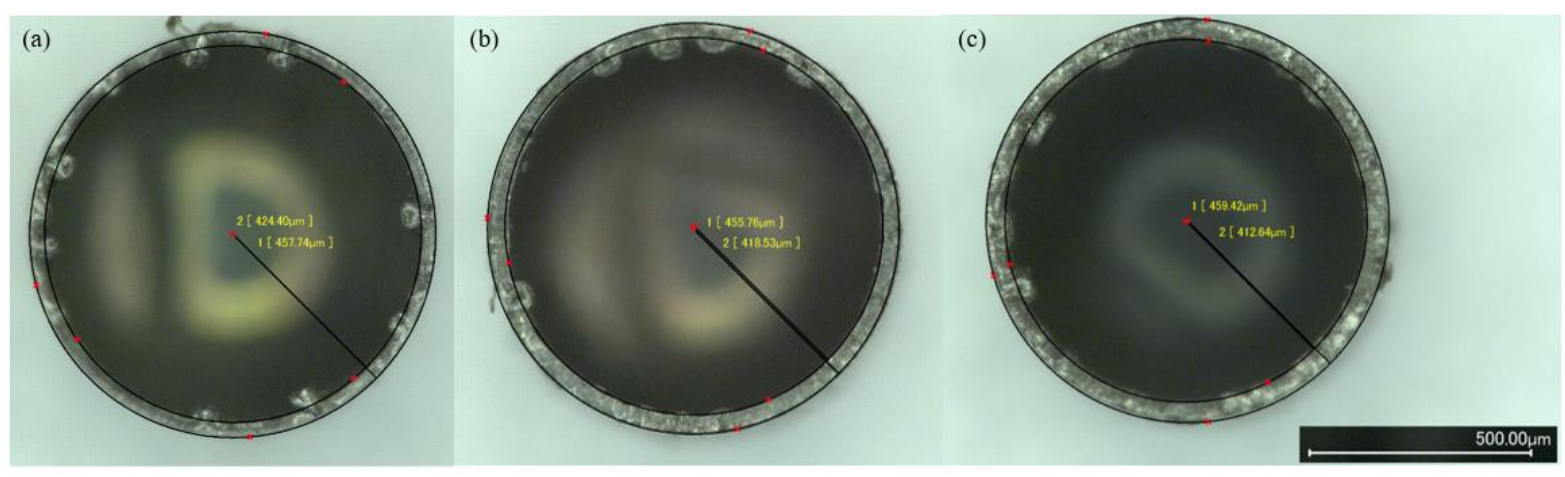

Fig. 7. Micro cup mouth view under $950{ }^{\circ} \mathrm{C}$ heat treatment with different blank thickness: (a) 0.03 $\mathrm{mm}$, (b) $0.04 \mathrm{~mm}$, and (c) $0.05 \mathrm{~mm}$

(a)

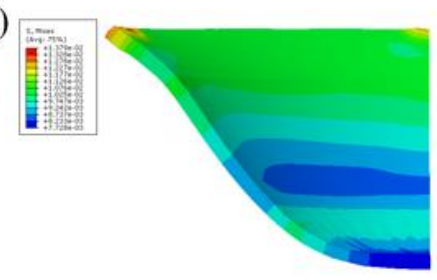

(b)

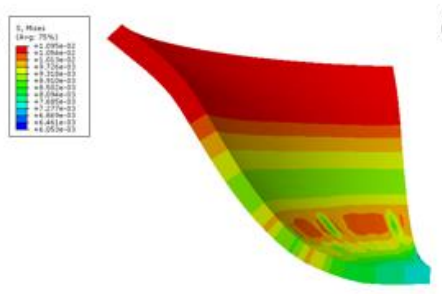

(c)

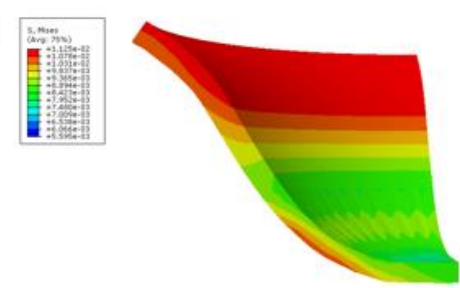

Fig. 8. Blank stress state under $950{ }^{\circ} \mathrm{C}$ heat treatment with different blank thickness: (a) $0.03 \mathrm{~mm}$, (b) $0.04 \mathrm{~mm}$, and (c) $0.05 \mathrm{~mm}$ 

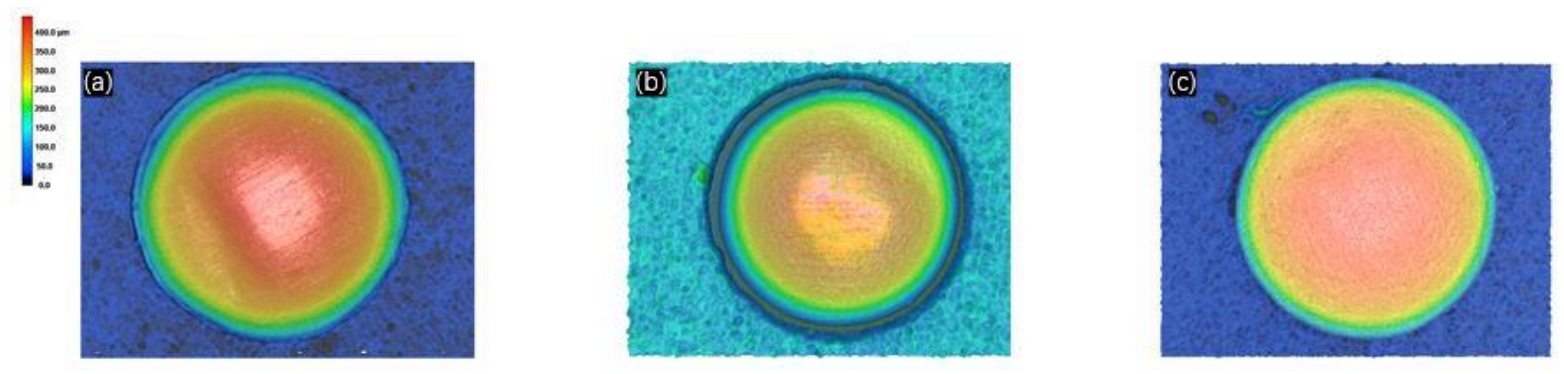

Fig. 9. Micro cup bottom view under $950{ }^{\circ} \mathrm{C}$ heat treatment with different blank thickness: (a) 0.03 $\mathrm{mm}$, (b) $0.04 \mathrm{~mm}$, and (c) $0.05 \mathrm{~mm}$

The micro cups can be formed by the MDD apparatus with different thickness blanks under different drawing velocities, and Fig. 10 shows the cup mouth view under these conditions. For all thickness blank, wrinkling occurred at the cup mouth with different drawing velocities. As can be seen, the wrinkling decreases with a rise of blank thickness, and the $0.03 \mathrm{~mm}$ micro cup has the most significant wrinkling phenomenon among these different conditions. Generally, the amount of wrinkling point increases and the wrinkling degree becomes more obvious with an increase of drawing velocity, when the blank thickness is $0.03 \mathrm{~mm}$ or $0.04 \mathrm{~mm}$. However, the wrinkling point on the micro cup mouth of the $0.05 \mathrm{~mm}$ blank does not transform apparently under different drawing velocities. In the beginning of drawing stage, the blank edge is fixed by the die sets, and this edge will slip into the die cavity as the forming process. Meanwhile, the blank holder provides the constant pressure on the fixed area, which can be decreased more easily with a thinner blank. Besides, the BHF decreased significantly with minimising the fixed area, and the wrinkling can be caused due to the insufficient BHF. Furthermore, the uneven deformation on the blank flange can also cause the wrinkling, and this deformation can be easily generated with the high stain rate on the flange. The drawing velocity can influence the stress in the blank edge, and the larger flow stress can cause the inhomogeneous deformation more easily. Nevertheless, the low drawing velocity can also increase the time of drawing process, then increase the probability of inhomogeneous deformation, and this effect is more significant with the insufficient BHF. Therefore, the number of the wrinkling point with $0.05 \mathrm{~mm}$ blank increases slightly with a decrease of drawing velocity, and the quantity of wrinkling points increases obvious when the blank thickness is 0.03 or $0.04 \mathrm{~mm}$. The MDD process with different blank thickness and drawing velocity is simulated via ABAQUAS, and the strain states of micro cup in simulation are illustrated in Figs. 11, 12, and 13 with 0.03, 0.04, and $0.05 \mathrm{~mm}$ blank thickness, respectively. As shown in the simulation results, the strain states are various in these conditions, and the difference of the strain on the micro cup mouth minimises with a rise of the blank thickness, which can cause the wrinkling phenomenon. When the thickness is 0.03 or $0.04 \mathrm{~mm}$, the strain on the micro cup mouth increases with a rise of the drawing velocity, and the difference of strain also becomes 
significant. However, the value and difference of the strain do not change obviously with $0.05 \mathrm{~mm}$ blank.

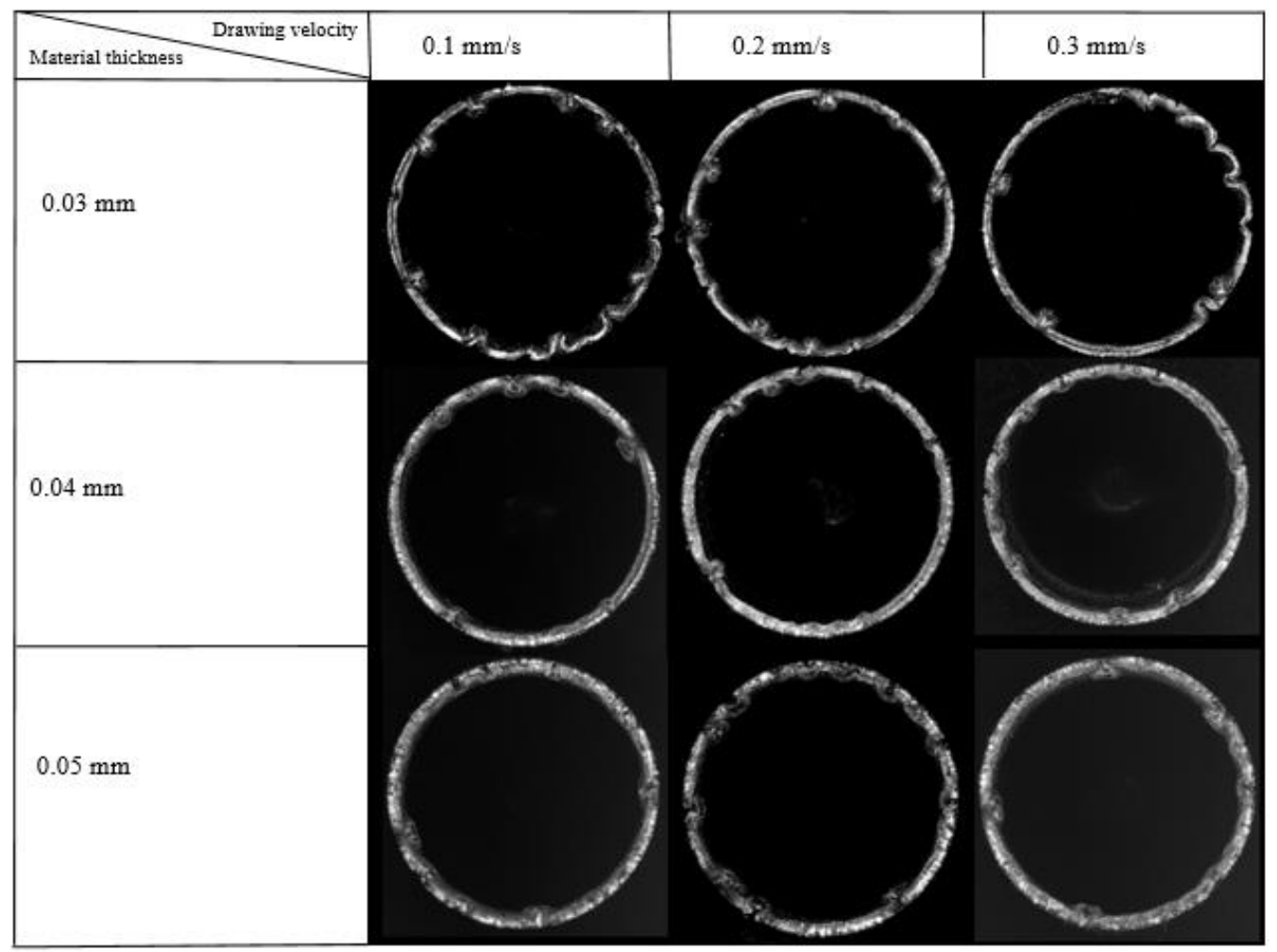

Fig. 10. Drawn cups' mouth view in different forming velocities with various thickness

(a)

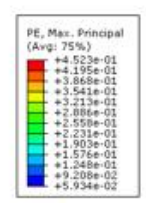

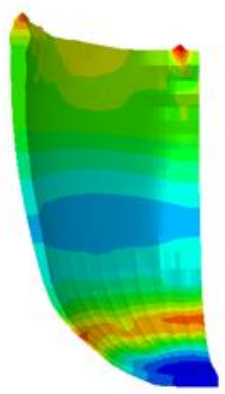

(b)

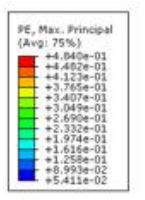

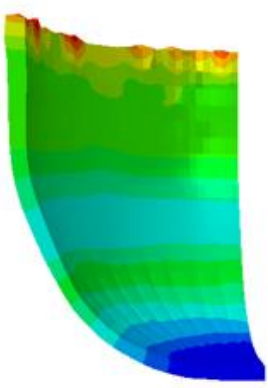

(c)
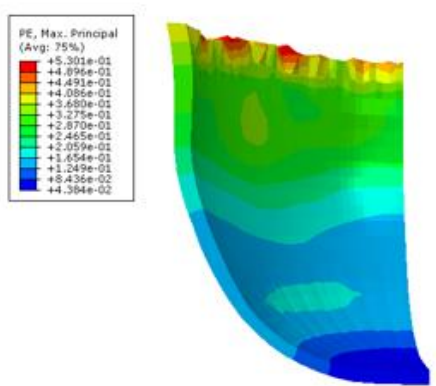

Fig. 11. Drawn cups' strain state with $0.03 \mathrm{~mm}$ blank in different forming velocities: (a) $0.1 \mathrm{~mm} / \mathrm{s}$, (b) $0.2 \mathrm{~mm} / \mathrm{s}$, and (c) $0.3 \mathrm{~mm} / \mathrm{s}$

(a)

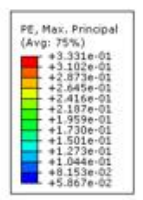

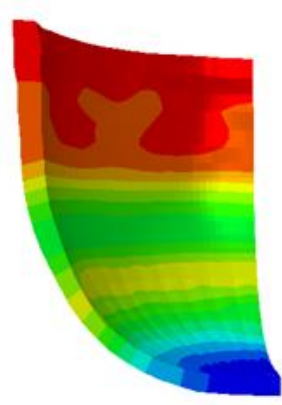

(b)

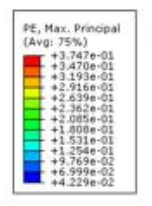

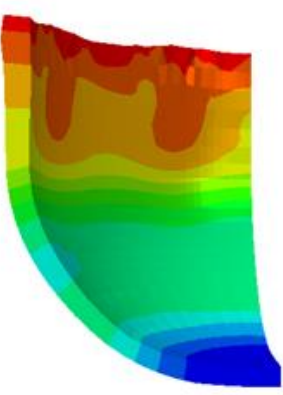

(c)
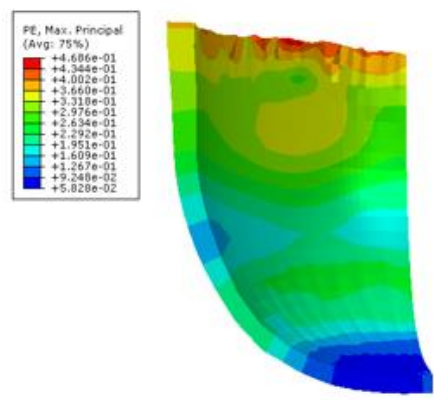
Fig. 12. Drawn cups' strain state with $0.04 \mathrm{~mm}$ blank in different forming velocities: (a) $0.1 \mathrm{~mm} / \mathrm{s}$, (b) $0.2 \mathrm{~mm} / \mathrm{s}$, and (c) $0.3 \mathrm{~mm} / \mathrm{s}$

(a)

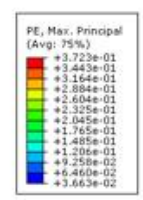

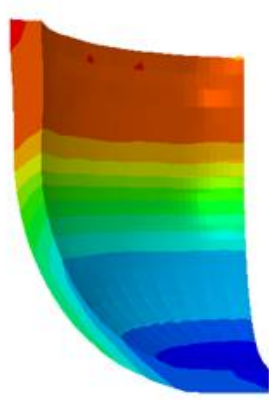

(b)

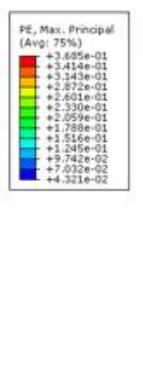

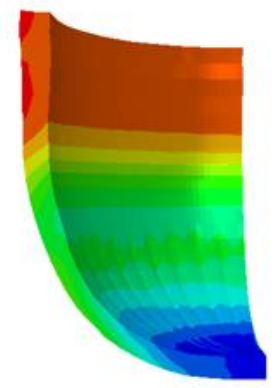

(c)

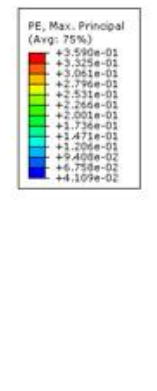

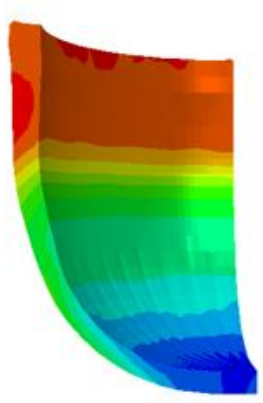

Fig. 13. Drawn cups' strain state with $0.05 \mathrm{~mm}$ blank in different forming velocities: (a) $0.1 \mathrm{~mm} / \mathrm{s}$, (b) $0.2 \mathrm{~mm} / \mathrm{s}$, and (c) $0.3 \mathrm{~mm} / \mathrm{s}$

The side view of micro cups with different blank thickness under various drawing velocity is shown in Fig. 13. Generally, the heights of micro cups with different blank thickness are not even under different drawing velocities, besides, the earing phenomenon of a thinner micro cup becomes more significant. Furthermore, the ear on the micro cup wall becomes more obvious with an increase of drawing velocity, and the earing phenomenon can be caused by unevenly distributed strain on the cup wall, and inhomogeneous material formability. From Fig. 14, the micro cup becomes evener with a thicker experimental sample or a rise of drawing velocity. Also, the scatter of material plastic deformation can affect the profile accuracy of micro products. In conclusion, the obvious earing phenomenon and the height unevenness appear significantly in the case of $0.03 \mathrm{~mm}$ micro cup, and it can be weakened by increasing the thickness or reducing the drawing velocity. 


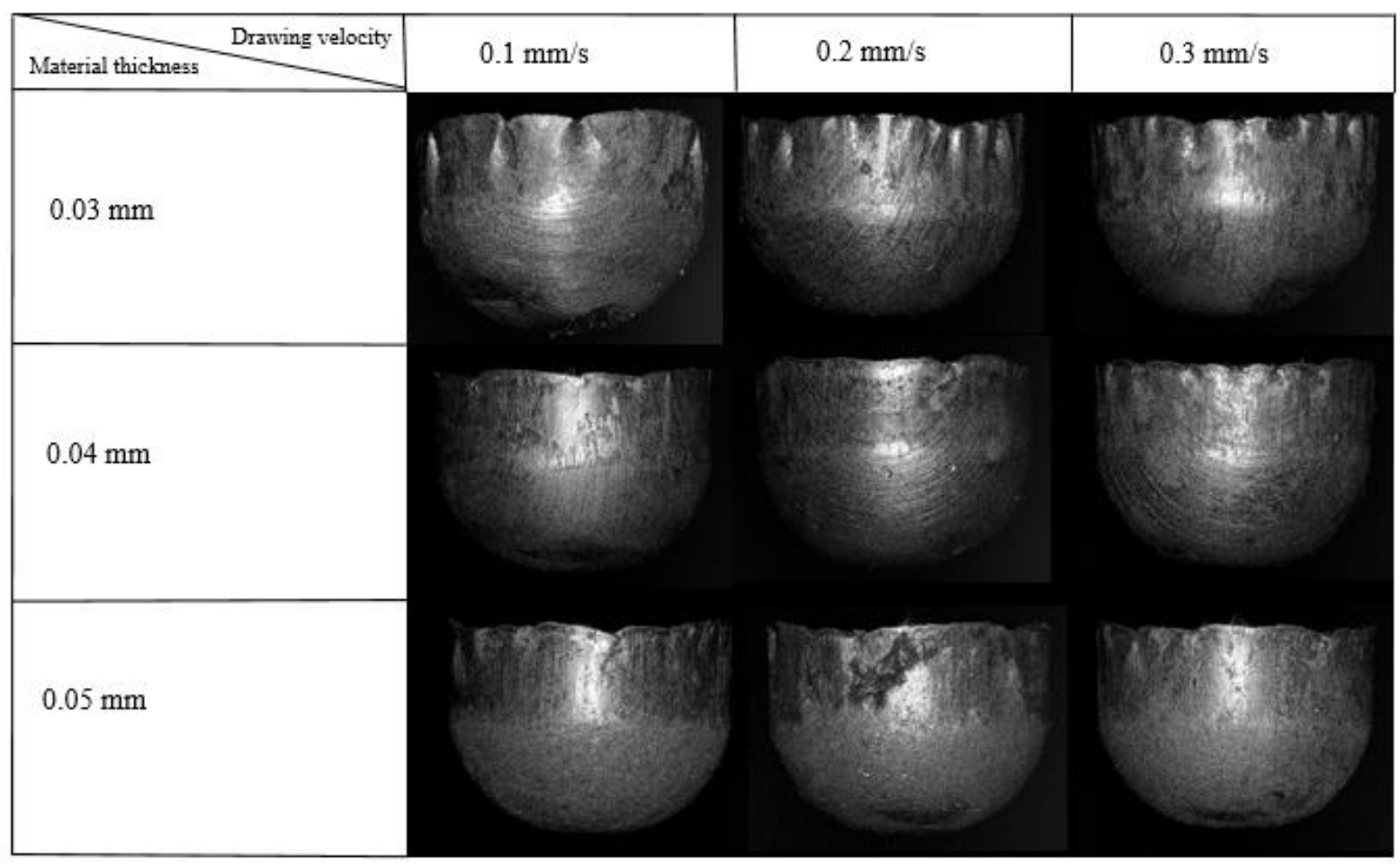

Fig. 14. Drawn cups' side-view in different forming velocities

To evaluate the surface quality of the micro cups, the surface roughness is measured, which can be influenced significantly by the tribological characteristic of the blank and tool interface. The middle point of the micro cup wall is selected for measurement, which is shown in Fig. 15. The surface roughness of this point is analysed, then the effect of altering drawing velocity on the micro cup quality with different thickness samples can be determined.

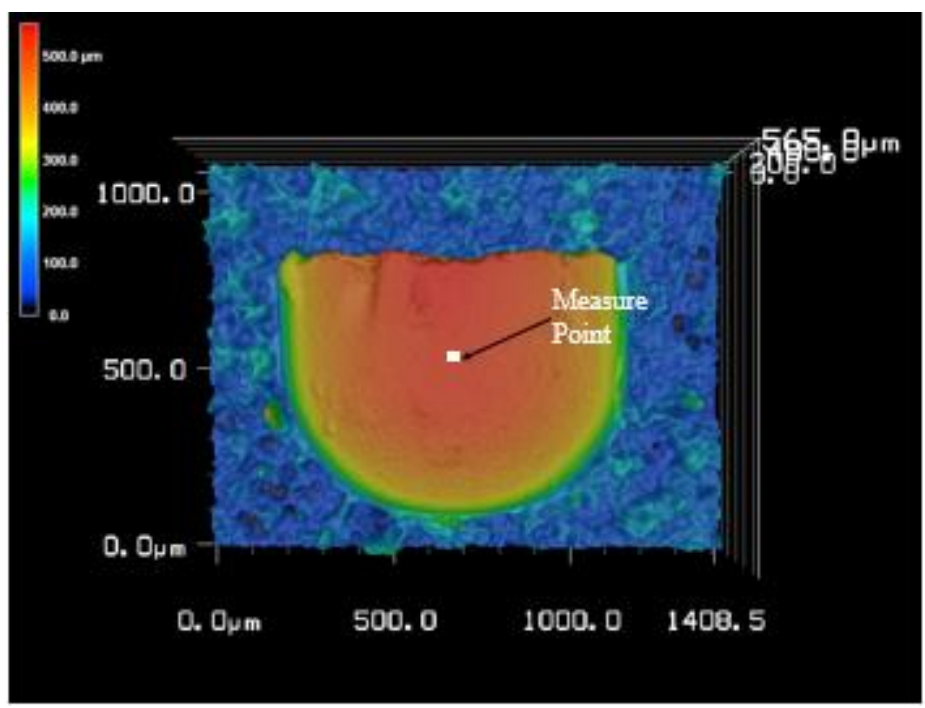

Fig. 15. The surface roughness measurement point 
The mean roughness $\left(R_{a}\right)$ and the height value of peaks and valleys $\left(R_{z}\right)$ are expressed as Eqs. (6) and (7) respectively to evaluate the surface roughness.

$$
\begin{gathered}
R_{a}=\left(\frac{1}{S}\right) \int_{0}^{S}\left|Z_{(x)}\right| d_{x} \\
R_{z}=R_{p}+R_{v}
\end{gathered}
$$

where $S$ is the evaluation length, $Z_{(x)}$ is the height function of the measured profile, $R_{p}$ is the maximum peak height and $R_{v}$ is the maximum valley height from average line.

Generally, the $R_{a}$ and $R_{z}$ values are nearly the same with different thickness samples before the drawing process, and these values are increased after the MDD, which means the material becomes rougher due to the formation. Figs. 16 and 17 show the $R_{a}$ and $R_{z}$ values of different thickness blanks with various drawing velocities after the MDD respectively, and the small $R_{a}$ value means the smooth and even surface. Generally, the $R_{a}$ and $R_{z}$ values decrease with $0.03 \mathrm{~mm}$ thickness sample due to a rise of drawing velocity, and the quantity between the maximum and minimum $R_{z}$ also reduces, which means the product's surface becomes even and smooth with a higher drawing velocity. The drawing time increases significantly with a lower forming velocity, and then the friction impact time can also increase, which can enhance the possibility of inhomogeneous forming. Furthermore, the different drawing velocities can cause various strain states during the MDD, the extending area of the cup wall could be larger with a lower drawing velocity before the blank contact the drawing cavity. Since the contact area expends significantly when the blank contact the die cavity, and the larger contact area can aggravate the effect of friction. Meanwhile, the drawing velocity can influence the forming behaviour of the experimental sample, and the degree of this influence could be various with different thickness blanks. The grain boundary of the surface layer can be more easily broken comparing with the inner grain, because the surface grain is softer. During the MDD, the blank is stretched, and the inner and surface material grains are formed. Besides, the different forming behaviour between the inner and surface grain can cause the surface defect of the micro cups. However, when the thickness is $0.03 \mathrm{~mm}$, this difference diminishes due to the high ratio of the surface grain, and the influence of drawing velocity can be weakened. The ratio between the surface and inner grain of the blank decreases significantly with a rise of the blank thickness, and the difference between the surface and inner grain could be more obvious, then the maximum $R_{z}$, minimum $R_{z}$, and $R_{a}$ values increase significantly. Thus, the micro cup surface could be rough and uneven with a rise of the blank thickness under the 0.1 or $0.2 \mathrm{~mm} / \mathrm{s}$ drawing velocity. However, the surface quality has an opposite trend under $0.3 \mathrm{~mm} / \mathrm{s}$ drawing velocity, since the extending area increases significantly when the blank thickness is 0.4 or $0.5 \mathrm{~mm}$ under $0.3 \mathrm{~mm} / \mathrm{s}$ drawing velocity, and the influence of the inhomogeneous forming 
behaviour is indistinct under this drawing velocity. Since, the surface quality could be determined by the stress of the micro cup, the stress states of micro cup in simulation are illustrated in Figs. 18, 19, and 20 with $0.03,0.04$, and $0.05 \mathrm{~mm}$ blank thickness respectively. In the micro cup wall area, the stress increases with a rise of blank thickness, and this stress also be enhanced when decreasing the drawing velocity. Furthermore, the stress distribution is more uniform in the same height area with a thinner blank, and this distribution becomes more homogeneous under a higher drawing velocity.

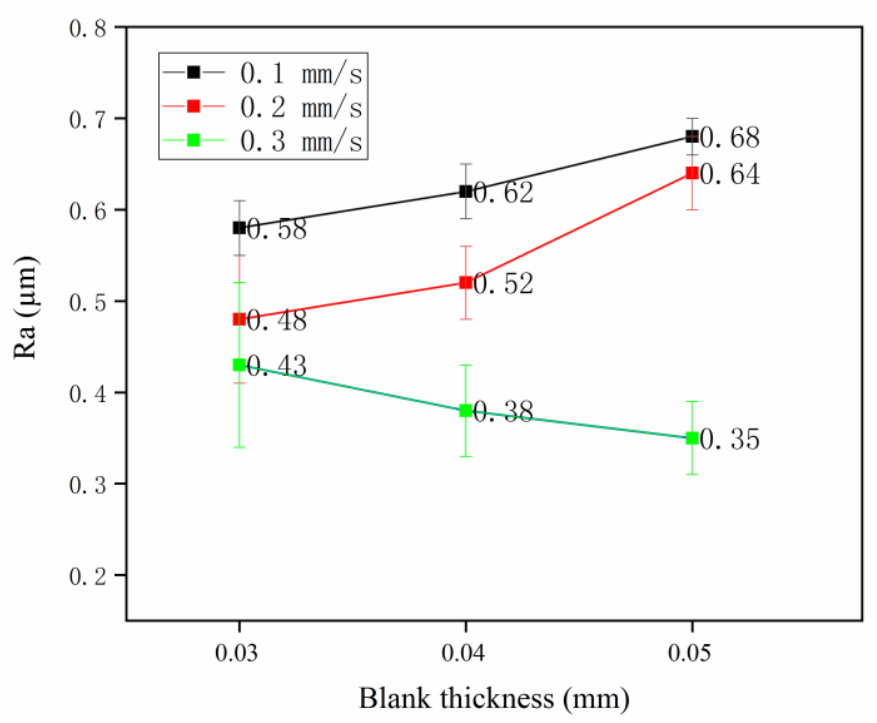

Fig. 16. The surface roughness by meaning of $R_{\mathrm{a}}$ 
(a)

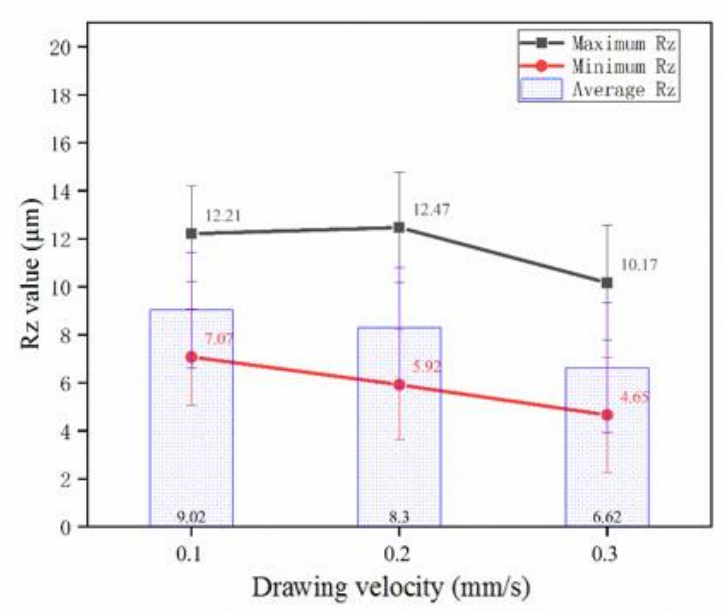

(c)

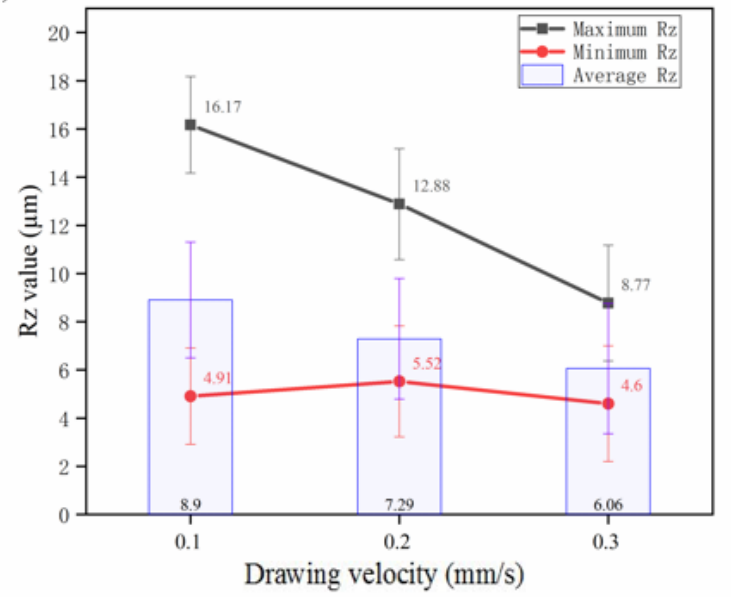

(b)

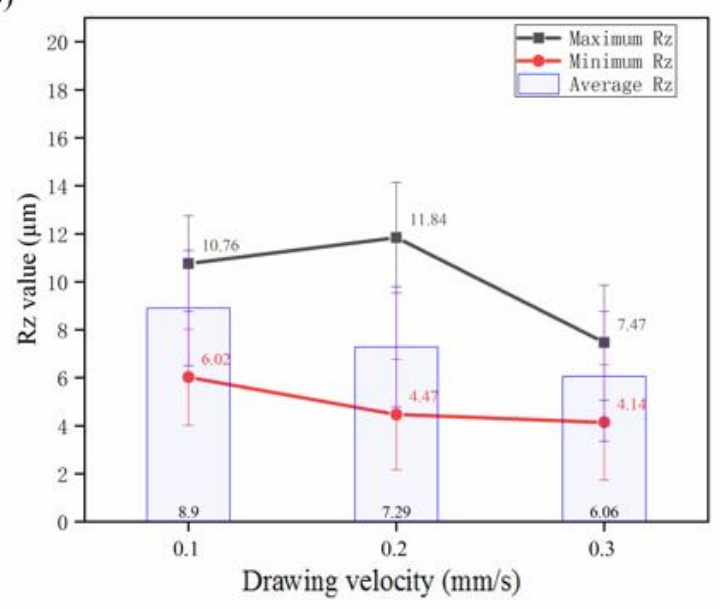

Fig. 17. The $R_{\mathrm{z}}$ value comparison of different blank thickness with different drawing velocity: (a) $0.03 \mathrm{~mm}$, (b) $0.04 \mathrm{~mm}$, and (c) $0.05 \mathrm{~mm}$

(a)

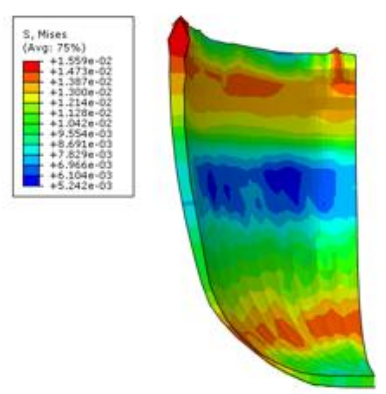

(b)

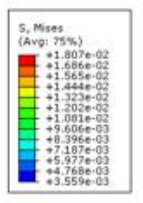

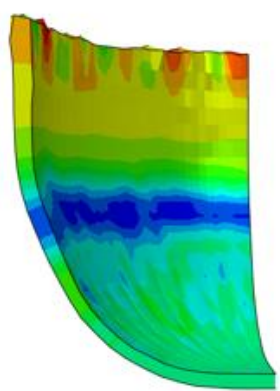

(c)

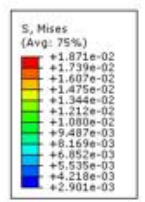

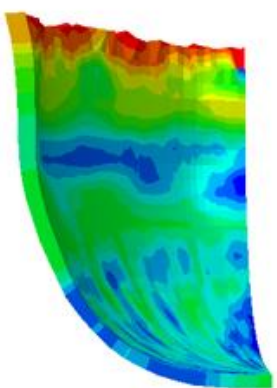

Fig. 18. Drawn cups' stress state with $0.03 \mathrm{~mm}$ blank in different forming velocities: (a) $0.1 \mathrm{~mm} / \mathrm{s}$, (b) $0.2 \mathrm{~mm} / \mathrm{s}$, and (c) $0.3 \mathrm{~mm} / \mathrm{s}$ 
(a)

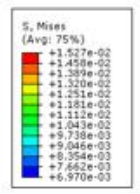

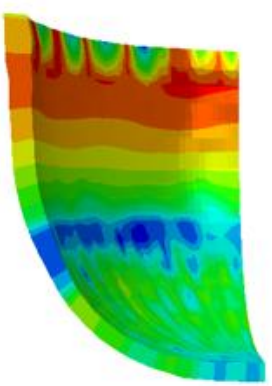

(b)

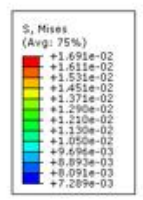

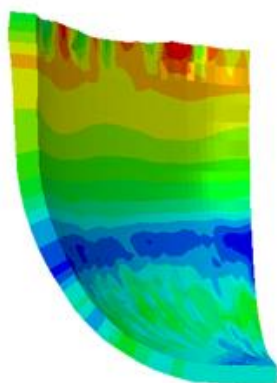

(c)

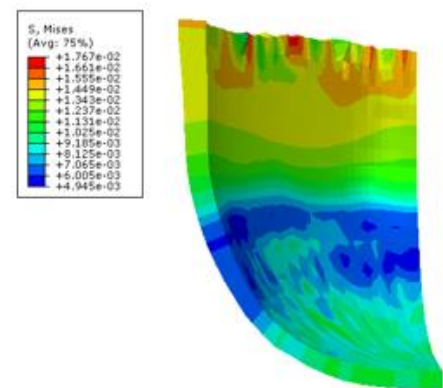

Fig. 19. Drawn cups' stress state with $0.04 \mathrm{~mm}$ blank in different forming velocities: (a) $0.1 \mathrm{~mm} / \mathrm{s}$, (b) $0.2 \mathrm{~mm} / \mathrm{s}$, and (c) $0.3 \mathrm{~mm} / \mathrm{s}$

(a)
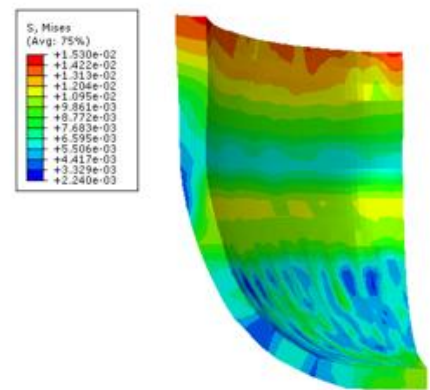

(b)

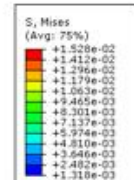

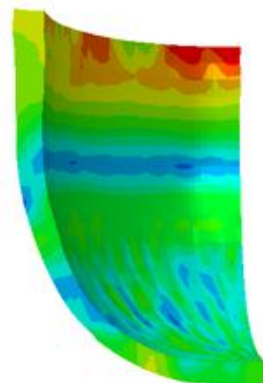

(c)

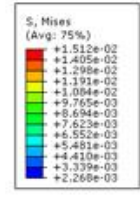

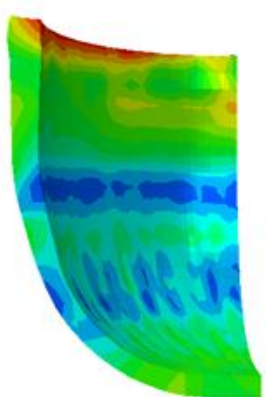

Fig. 20. Drawn cups' stress state with $0.05 \mathrm{~mm}$ blank in different forming velocities: (a) $0.1 \mathrm{~mm} / \mathrm{s}$, (b) $0.2 \mathrm{~mm} / \mathrm{s}$, and (c) $0.3 \mathrm{~mm} / \mathrm{s}$

\section{Conclusion}

This study presented an experimental research and numerical simulation on forming micro austenite SUS301 cups with different blank thickness under various blanking and forming velocities. The influence of forming velocity with different thickness blanks on drawn micro products' dimensional quality, drawing force, profile accuracy and surface quality were studied. The conclusions are as follows:

1. The drown product quality is affected with different blanking velocities and experimental blank thickness. $0.04 \mathrm{~mm}$ blank with $0.1 \mathrm{~mm} / \mathrm{s}$ blanking velocity has the best edge quality compared with other blanking velocity and thickness. When the blank thickness increases, the effect of the blanking velocity on the side quality of drawn micro products becomes more significantly. More burr and uneven area can be generated with a higher blanking velocity, and the blank quality is crucial to determine the product's quality in the next forming stage.

2. The profile of micro cup can be modified by changing the blank thickness and forming velocity. It was found that, the micro cup has less indentation area, and becomes more round and symmetrical with a thicker blank. Furthermore, the wrinkling phenomenon becomes distinct with a decrease of blank thickness. The amount of wrinkling point increases and the 
wrinkling degree becomes more obvious with a rise of drawing velocity. The heights of micro cups are not even with different blank thickness under different drawing velocities, and the earing phenomenon becomes more significant with an increase of drawing velocity and a decrease of the blank thickness.

3. The surface quality could be improved by changing the drawing velocity and experimental material thickness. When increasing the drawing velocity or blank thickness, the surface becomes smooth and even. Furthermore, the micro cup surface could be rough and uneven with a rise of the blank thickness under the 0.1 or $0.2 \mathrm{~mm} / \mathrm{s}$ drawing velocity, and the surface quality has an opposite trend when the drawing velocity is $0.3 \mathrm{~mm} / \mathrm{s}$.

4. Comparing the experimental and simulation results, the stress and strain states are various with different thickness blanks or drawing velocities. Besides, the influence of the drawing velocity on various thickness blank are close between the results of experiments and FE model, which confirms the developed FE model is applicable.

Authors contributions This manuscript is the original work of all authors. The authors declare that all authors were fully involved in the study and preparation of the manuscript.

Funding This work is support by Australian Research Council Discovery Project, and the first author also appreciates UOW support for the International Postgraduate Tuition Award (IPTA) scholarship for this current study.

Data Availability The data and materials supporting the results of this article are included within the article.

\section{Declarations}

Ethical approval The authors declare that there are no conflicts with the ethical standards by Springer and the research conducted in context of this research paper.

Consent to participate No research involving human subjects has been conducted in context of this publication and thus, a consent to participate is not needed.

Consent to publish No research involving private companies has been conducted in context of this publication and thus, a consent to publish is not needed.

Competing interests The authors declare no competing interests 


\section{References}

[1] C. Barbier, S. Thibaud, F. Richard, and P. Picart (2009) Size effects on material behavior in microforming. Int J Mater Form 2: 625. https://doi.org/10.1007/s12289-009-0563-0

[2] T. Shimizu, Y. Murashige, S. Iwaoka, M. Yang, and K.-I. Manabe (2013) Scale dependence of adhesion behavior under dry friction in progressive micro-deep drawing. Journal of Solid Mechanics and Materials Engineering 7: 251-263.https://oi.org/10.1299/jmmp.7.251

[3] F.-K. Chen and J.-W. Tsai (2006) A study of size effect in micro-forming with micro-hardness $\begin{array}{llllll}\text { tests. } & \text { J Mater } & \text { Process }\end{array}$ https://doi.org/10.1016/j.jmatprotec.2006.04.115

[4] W. Chan, M. Fu, J. Lu, and J. Liu (2010) Modeling of grain size effect on micro deformation behavior in micro-forming of pure copper. Mater Sci Eng A 527: 6638-6648. https://doi.org/10.1016/j.msea.2010.07.009

[5] M. Fu and W. Chan (2013) A review on the state-of-the-art microforming technologies. Int J Adv Manuf Technol 67: 2411-2437.

[6] C. Wang et al. (2018) Size effect affected mechanical properties and formability in micro plane strain deformation process of pure nickel. J Mater Process Technol 258: 319-325. https://doi.org/10.1016/j.jmatprotec.2018.04.001

[7] M. Fu and W. Chan (2013) Micro-scaled progressive forming of bulk micropart via directly using sheet metals. Mater Des 49: 774-783. https//doi.org/10.1016/j.matdes.2013.02.045

[8] J.-T. Gau, S. Teegala, K.-M. Huang, T.-J. Hsiao, and B.-T. Lin (2013) Using micro deep drawing with ironing stages to form stainless steel 304 micro cups. J Manuf Processes 15: 298-305. https://doi.org/10.1016/j.jmapro.2013.01.009

[9] D. Lu, Y. Yang, Y. Qin, and G. Yang (2012) Effect of particle size and sintering temperature on densification during coupled multifield-activated microforming. J Mater Res 27: 2579. https://oi.org/10.1557/jmr.2012.262

[10] J. Zheng, H. Yang, M. Fu, and C. Ng (2019) Study on size effect affected progressive microforming of conical flanged parts directly using sheet metals. J Mater Process Technol 272: 72-86. https://doi.org/10.1016/j.jmatprotec.2019.05.007

[11] M. Hasan, J. Zhao, and Z. Jiang (2019) Micromanufacturing of composite materials: a review. Int J Extreme Manuf 1: 012004. https://doi.org/10.1088/2631-7990/ab0f74

[12] H. Hoffmann and S. Hong (2006) Tensile Test of very thin Sheet Metal and Determination of Flow Stress Considering the Scaling Effect. CIRP Ann 55: 263-266. https://doi.org/10.1016/s0007-8506(07)60412-0

[13] A. R. Razali and Y. Qin (2013) A review on micro-manufacturing, microforming and their key issues. Procedia Eng 53: 665-672. https//doi.org/10.1016/j.proeng.2013.02.086

[14] X. Wang et al. (2016) Size effects on flow stress behavior during electrically-assisted microtension in a magnesium alloy AZ31. Mater Sci Eng A 659: 215-224. https://doi.org/10.1016/j.msea.2016.02.064

[15] F.-H. Yeh, C.-L. Li, and Y.-H. Lu (2008) Study of thickness and grain size effects on material behavior in micro-forming. J Mater Process Technol 201: 237-241. https://doi.org/10.1016/j.jmatprotec.2007.11.138

[16] H. Justinger and G. Hirt (2009) Estimation of grain size and grain orientation influence in microforming processes by Taylor factor considerations. J Mater Process Technol 209: 21112121. https:/doi.org/10.1016/j.jmatprotec.2008.05.008

[17] H. Kamali et al. (2019) Effects of nano-particle lubrication on micro deep drawing of $\mathrm{Mg}-\mathrm{Li}$ alloy. Int J Adv Manuf Technol 104: 4409-4419. https://doi.org/10.1007/s00170-019-04267$\mathrm{z}$ 
[18] H. Kim and Y. Lee (2012) Size dependence of flow stress and plastic behaviour in microforming of polycrystalline metallic materials. Proc Inst Mech Eng C J Mech Eng Sci P I MECH ENG C-J MEC 226: 403-412. https://doi.org/10.1177/0954406211414473

[19] H. Sato, K. Manabe, K. Ito, D. Wei, and Z. Jiang (2015) Development of servo-type microhydromechanical deep-drawing apparatus and micro deep-drawing experiments of circular $\begin{array}{lllll}\text { cups. } & \text { J } & \text { 233-239. }\end{array}$ https://doi.org/10.1016/j.jmatprotec.2015.05.014

[20] I. Irthiea, G. Green, S. Hashim, and A. Kriama (2014) Experimental and numerical investigation on micro deep drawing process of stainless steel 304 foil using flexible tools. Int J Mach Tools Manuf 76: 21-33. https//doi.org/10.1016/j.ijmachtools.2013.09.006

[21] L. Luo, Z. Jiang, D. Wei, and F. Jia (2021) A study of influence of hydraulic pressure on micro-hydromechanical deep drawing considering size effects and surface roughness. Wear 203803. https://doi.org/10.1016/j.wear.2021.203803

[22] L. Luo et al. (2016) Effects of surface roughness on micro deep drawing of circular cups with consideration of size effects. Finite Elem Anal Des 111: 46-55. https://doi.org/10.1016/j. fine1.2015.11.005

[23] L. Luo, D. Wei, G. Zu, and Z. Jiang (2021) Influence of blank holder-die gap on micro-deep drawing of SUS304 cups. Int J Mech Sci 191: 106065. https://doi.org/10.1016/j.ijmecsci.2020.106065

[24] L. Luo, Z. Jiang, and D. Wei (2017) Influences of micro-friction on surface finish in micro deep drawing of SUS304 cups. Wear 374-375: 36-45. https://doi.org/10.1016/j.wear.2016.11.043

[25] Z. Hu, A. Schubnov, and F. Vollertsen (2012) Tribological behaviour of DLC-films and their application in micro deep drawing. J Mater Process Technol 212: 647-652. https://doi.org/10.1016/j.jmatprotec.2011.10.012

[26] W. Liu and S. Chen (2000) An investigation of the tribological behaviour of surface-modified $\mathrm{ZnS}$ nanoparticles in liquid paraffin. Wear 238: 120-124. https:/doi.org/10.1016/S00431648(99)00344-0

[27] C. Wang, B. Guo, D. Shan, M. Zhang, and X. Bai (2014) Tribological behaviors in microforming considering microscopically trapped lubricant at contact interface. Int $\mathrm{J} \mathrm{Adv}$ Manuf Technol 71: 2083-2090. http//dx.doi.org/10.1007/s00170-014-5657-2

[28] B. Zareh-Desari, M. Abaszadeh-Yakhforvazani, and S. Khalilpourazary (2015) The effect of nanoparticle additives on lubrication performance in deep drawing process: evaluation of forming load, friction coefficient and surface quality. Int J Precis Eng Manuf 16: 929-936. https://doi-org.ezproxy.uow.edu.au/10.1007/s12541-015-0121-2

[29] W. Xia et al. (2018) Analysis of oil-in-water based nanolubricants with varying mass fractions of oil and TiO 2 nanoparticles. Wear 396-397: 162-171. https://doi.org/10.1016/j.wear.2017.02.031

[30] W. Xia et al. (2016) Effects of Nano-TiO2 Additive in Oil-in-Water Lubricant on Contact Angle and Antiscratch Behavior. Tribol Trans 60: 362-372. https://doi.org/10.1080/10402004.2016.1168900

[31] H. Wu et al. (2017) Analysis of TiO 2 nano-additive water-based lubricants in hot rolling of $\begin{array}{lllll}\text { microalloyed } & \text { steel. } & \mathrm{J} & \text { Manuf 26-36. }\end{array}$ https://doi.org/10.1016/j.jmapro.2017.03.011

[32] F. Vollertsen and Z. Hu (2010) Analysis of punch velocity dependent process window in micro deep drawing. Prod Eng 4: 553-559. https://doi.org/10.1007/s11740-010-0241-6

[33] K. Zhang and L. Kun (2009) Classification of size effects and similarity evaluating method in micro forming. J Mater Process Technol 209: 4949-4953. https://doi.org/10.1016/j.jmatprotec.2008.11.018

[34] Z. Li et al. (2018) Analysis of bending characteristics of bimetal steel composite. Int J Mech Sci 148: 272-283. https://doi.org/10.1016/j.ijmecsci.2018.08.032 
[35] T. Yalçinkaya, İ. Özdemir, and I. Simonovski (2018) Micromechanical modeling of intrinsic and specimen size effects in microforming. Int $\mathrm{J}$ Mater Form 11: 729-741. https:/doi.org/10.1007/s12289-017-1390-3

[36] J. Zhao et al. (2021) Experimental Investigation on Micro Deep Drawing of Stainless Steel Foils with Different Microstructural Characteristics. Chin J Mech Eng 34: 1-11. https://doi.org/10.1186/s10033-021-00556-5

[37] X. Lai, L. Peng, P. Hu, S. Lan, and J. Ni (2008) Material behavior modelling in micro/mesoscale forming process with considering size/scale effects. Comput Mater Sci 43: 1003-1009. https://oi.org/10.1016/j.commatsci.2008.02.017 